Kohl: a Journal for Body and Gender Research

Vol. 6, No. 1 (Summer 2020)

\title{
Tears in the Fabric
}

Skinsells 
The illustrations portray a single organic body, representing a community or organization. In each illustration, we see this body interact with itself in a different manner, with hands branching out into different directions, mouths in conversation or disagreement, parts coming together to create something new, or moulding into something different altogether. These branches and tears in the fabric of the body represent the tensions within a community, that which fosters multiple ideologies under its title, that clash or learn from each other, which may reform and grow into something evolved, or may separate from the group, no longer identifying with the whole.

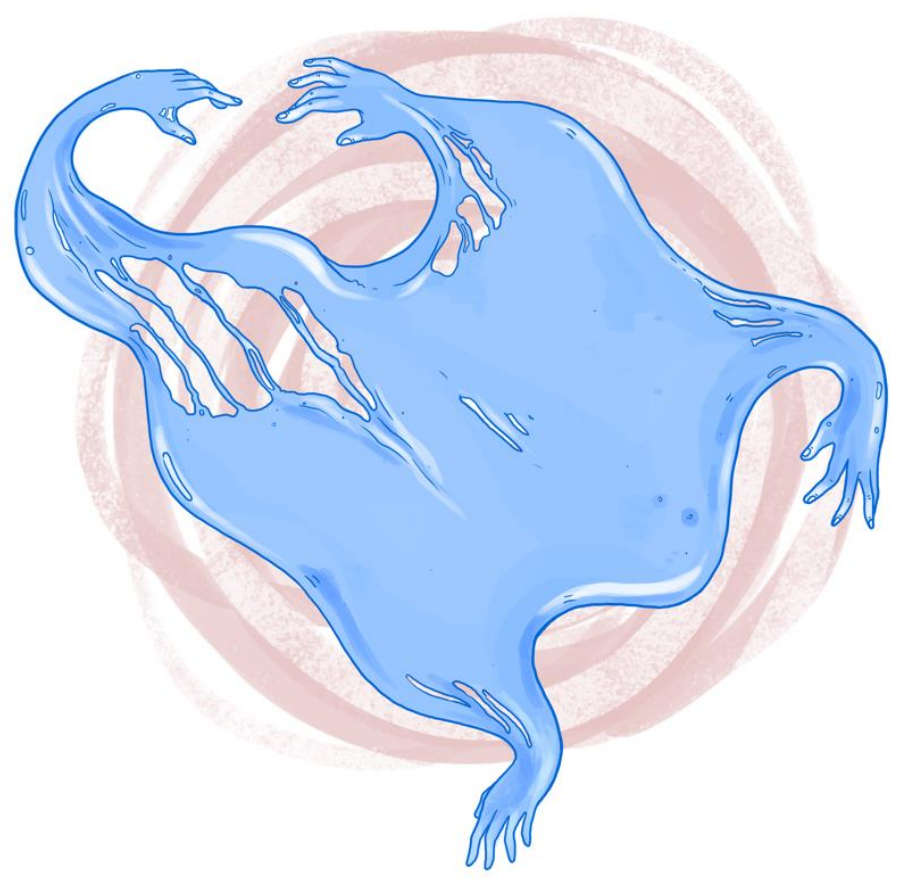

Image 1 - Tears in the fabric 


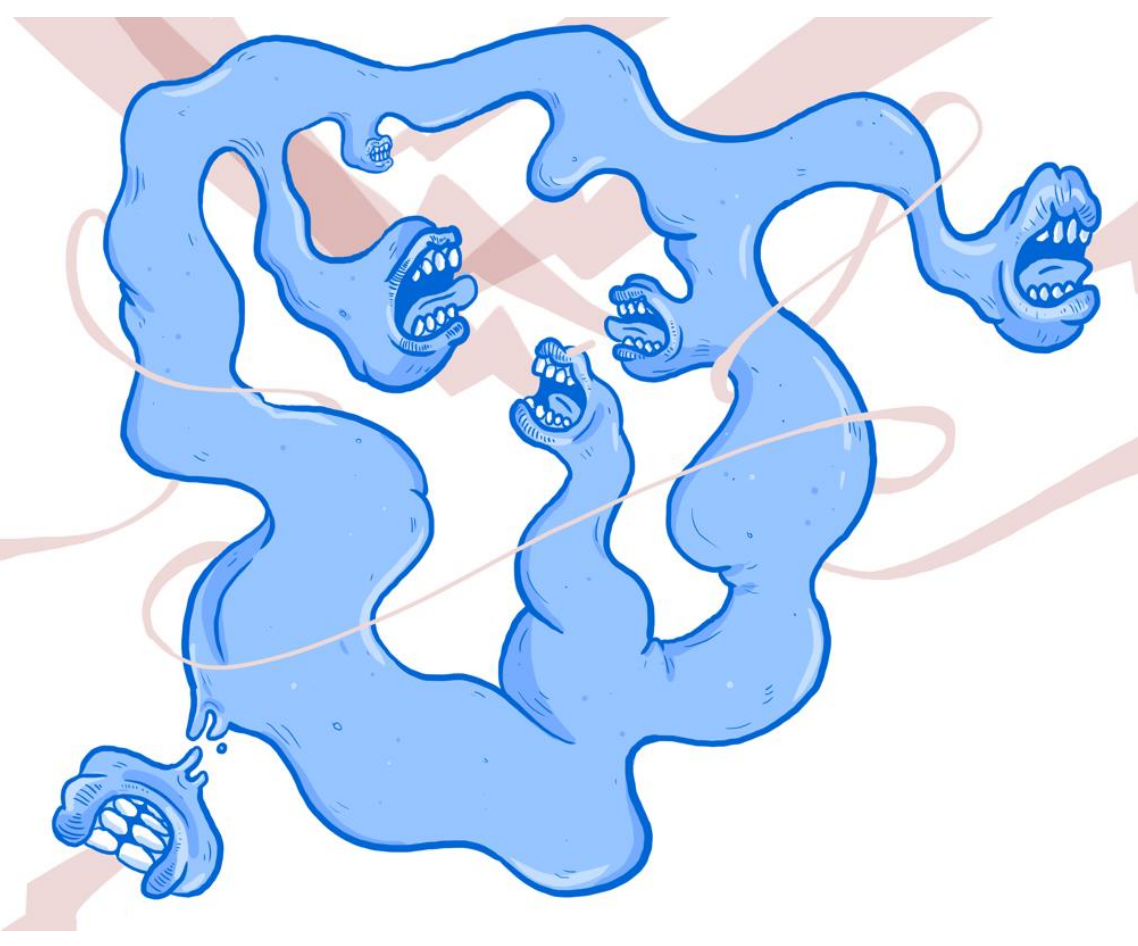

Image 2 - Internal Clash

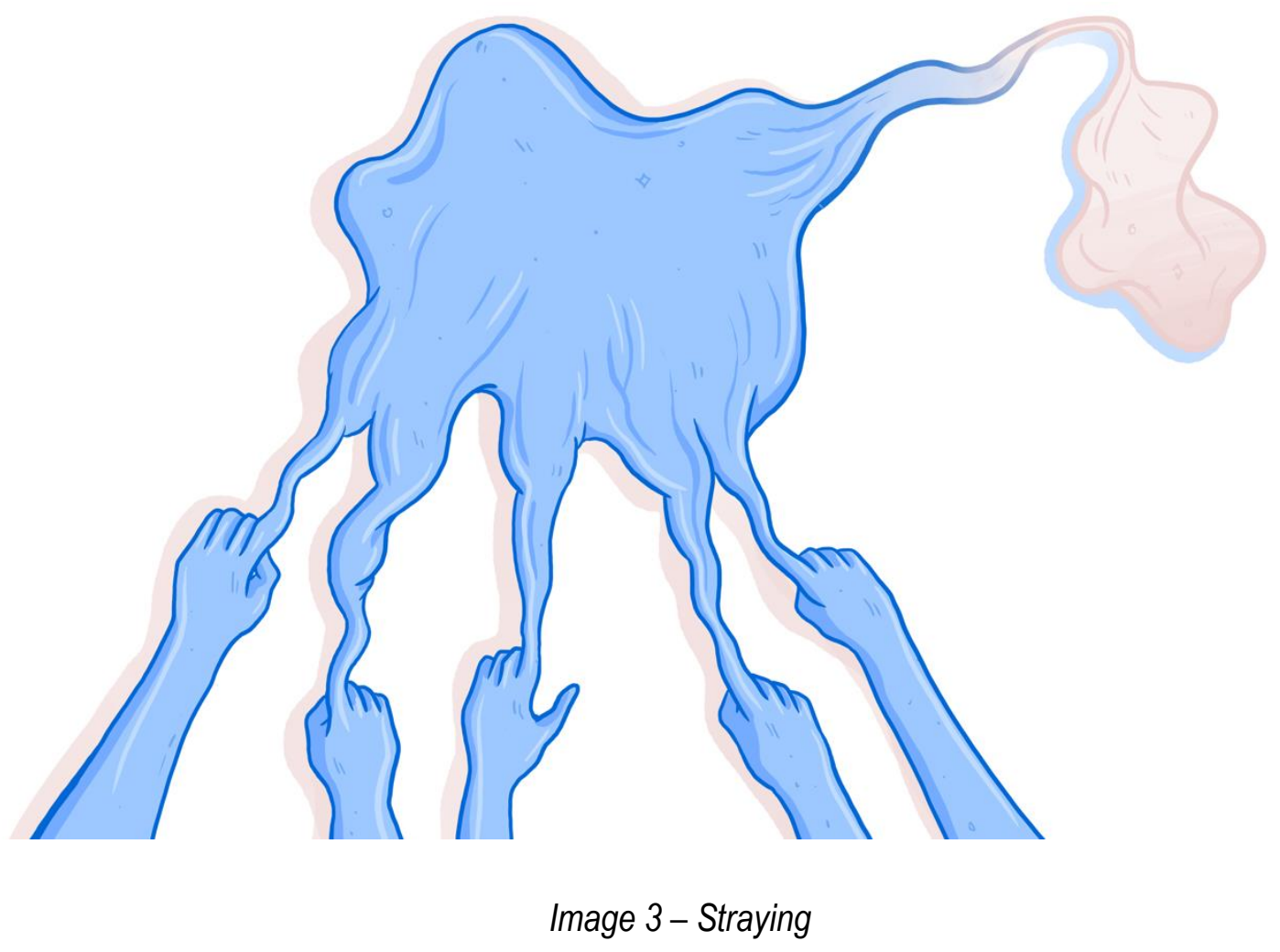


Kohl 6.1

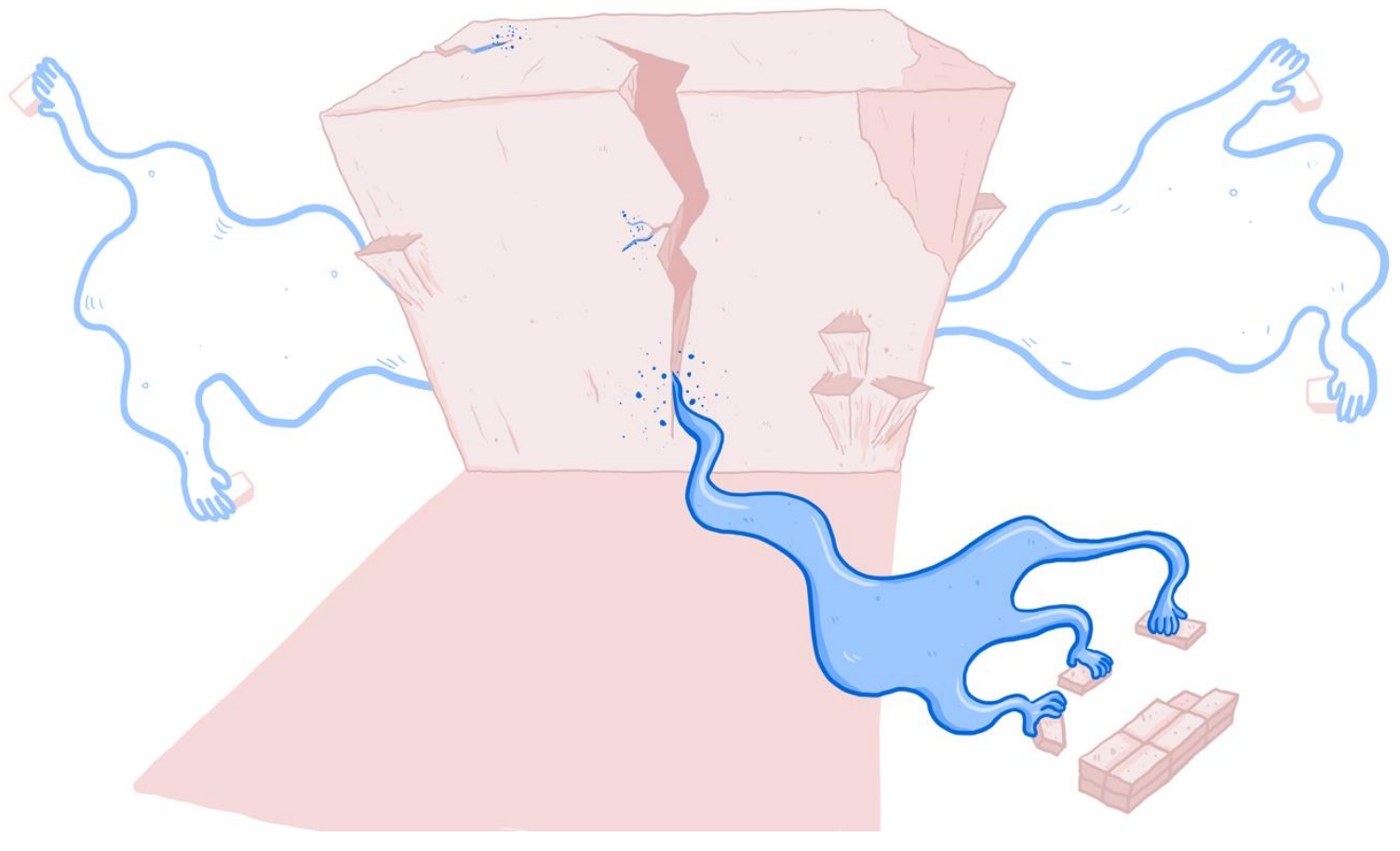

Image 4-Reform / Through the Cracks 